\title{
La Vinculacion De Los Conocimientos Academicos Y Los Saberes Ancestrales En La Educacion Básica Intercultural En Presidio De Los Reyes, Nayarit México
}

\author{
PhD María del Carmen Hernández Cueto \\ PhD María del Refugio Navarro Hernández \\ Master Lía Márquez Pérez \\ Universidad Autonoma de Nayarit, Mexico
}

Doi:10.19044/esj.2018.v14n28p136 URL:http://dx.doi.org/10.19044/esj.2018.v14n28p136

\begin{abstract}
This paper focuses on analyzing the teaching-learning process that takes place in second level basic education in the community of Presidio de los Reyes in Nayarit, Mexico. The study aims at knowing if this links the ancestral knowledge of the Naayeri community (Cora) with the official academic curriculum of the Ministry of Public Education (MPE). The study sample were the teachers and the management staff of Pentecatl Elementary located in a community in Cora baja, in the municipality of Ruiz in Nayarit, Mexico. The methodology of this study was transversal for one year and then qualitative. The instruments used in this study was a semi-structured interview about the knowledge of the basic education profile, as well as the analysis of the teaching sequences of the teachers. The results of the research show how teachers promote traditional knowledge, culture, and the learning of the Cora language as a national language and not as a mother tongue. They design materials and perform activities that relates and links traditional knowledge with academics. They also establish approaches with the traditional authorities, and bridges are being constructed that intertwine the ancestral knowledge with the academic contents proposed by the MPE.
\end{abstract}

Keywords: link, teaching-learning, traditional knowledges, Naayerì, academic knowledge

\section{Resumen}

La investigación analiza el proceso de enseñanza-aprendizaje que se lleva a cabo en la educación básica de segundo nivel en la comunidad de Presidio de los Reyes en Nayarit, México, esto con el propósito de conocer si 
éste vincula los saberes ancestrales de la comunidad Naayeri (Cora) con el currículo académico oficial de la Secretaría de Educación Pública (SEP). El objeto de este estudio fueron los docentes y el personal directivo de la Primaria Pentecatl ubicada en una comunidad de la Cora baja, en el municipio de Ruiz en Nayarit, México. La metodología de esta indagación fue transversal por un año y luego cualitativa. Los instrumentos que se utilizaron fueron la entrevista semiestructurada acerca del conocimiento del perfil docente de nivel básico, al igual que el análisis de las secuencias didácticas de los docentes. Los resultados arrojados porla investigación muestran cómo los docentes fomentan saberes tradicionales coras, la cultura y el aprendizaje de la lengua Cora en tanto como lengua nacional y no como lengua materna; diseñan materiales y hacen actividades que relacionan y vinculan los saberes tradicionales con los académicos, se establecen acercamientos con las Autoridades tradicionales, y se están construyendo puentes que entrelazan los saberes ancestrales con los contenidos académicos que propone la SEP.

Palabras clave: vinculación, enseñanza-aprendizaje, saberes tradicionales, Naayerì, conocimiento academico

\section{Introducción}

Los procesos de extinción de las culturas de los pueblos originarios a los que estos últimos se han visto arrastrados han adquirido una velocidad mayor con la incorporación de las nuevas tecnologías y la exposicióninevitable a cómo el progreso nacional puede impactar las comunidades geográfica y económicamente marginadas. Estas comunidadespresentan condiciones educativas en el nivel básico que es necesario medir, evaluar y estudiar para direccionar metodologías específicas que reviertan la destrucción de sus cosmovisiones, tradiciones y formas de vida.

El sistema nacional de educación básica establece en los estándares curriculares los aprendizajes esperados que debe demostrar cada estudiante con respecto a los propósitos generales del plan de estudio sin distinguir a nadie; es decir, se aplica a toda la educación básica del país. Sin embargo, en estas comunidades inter y multiculturales con carencias, limitaciones y menos oportunidades de desarrollo, lograr el objetivo de los aprendizajes esperados se vuelve una utopía, en vista de que ni los profesores, ni las instalaciones, ni la comunidad tienen los recursos suficientes tanto académicos como de infraestructura, situación que se expresa en los bajos rendimientos escolares, deserción y un pobre desempeño docente.

De acuerdo a lo anterior y a la incapacidad de las autoridades para tomar decisiones y orientar apoyo académico y económico, se deja a estas poblaciones a su suerte, formando un circulo vicioso del cual no pueden salir, y donde cada vez más hay menor calidad educativa. 
De esta manera, se deja en desventaja estructural a las etnias y en consecuencia al docente y directivos de las escuelas que saben que el apoyo para estas zonas geográficas es muy limitado. El acceso a las comunicaciones no es comercial para las empresas y, por lo tanto, no tienen inversiones en estas zonas conocidas por su pobreza extrema y alta peligrosidad.

Así, en este contexto, el proceso de enseñanza-aprendizaje es llevado a cabo con muchas limitaciones y problemas que llevan a niños y docentes a fracasar. El aislamiento de sus comunidades, como se había dicho anteriormente, los hace invisibles para la Secretaría de Educación Publica en lo que respecta a presupuestos que se deberían de canalizar a estas comunidades y que no se realizan porque no se cuenta con los datos necesarios para crear fondos de apoyo a estas instituciones que tienen como objetivo la formación de niños y niñas de comunidades marginadas y aisladas quienes, en la mayoría de los casos, únicamente tendrán acceso a la educación básica en el trascurso de su vida.

La práctica docente en los contextos inter y multiculturales debería tener el apoyo y fondos suficientes dedicados a reforzar el proceso de enseñanza-aprendizaje de los grupos étnicos, los cuales tienen mucho que aportar a la cultura occidental. Sobre todo, no se deben perder sus conocimientos ancentrales, los cualeshan sobrevivido de generación en generación y cuyo valor cultural y lingüístico no se toma en cuenta a pesar de que son considerados como patrimonio de la nación“".

La práctica docente de las personas que se desempeñan en estos ambientes es loable, tomando en cuenta que a pesar de las limitaciones económicas, geográficas, culturales, lingüísticas, entre otras, logran llevar a cabo titánicamente su función.

La educación indígena, hoy en día, tiene acceso a la calidad y la pertinencia de la enseñanza en tela de juicio. La educación en México ha existido desde la epoca prehispanica, si recordamos el Calmecac, ó Telpochcalli, escuelas dedicadas a formar a los jóvenes. Durante la conquista y por mandato de los reyes de España se inició la educación indígena donde, desde luego, fue el clero el encargado de ello con dos objetivos: i) evangelizarlos y ii) entrenamiento para el trabajo. De acuerdo con Gonzalbo y Ossenbach (1999), Carlos V. destacó la importancia de una educación integral y consideró que en el caso de los indígenas estos deberían ser instruidos tanto en la fé como en la conducta.

En el siglo XVIII se crearon las escuelas de lengua castellana para que los hijos de los indios aprendieran a hablar, leer y escribir en esta lengua, incluso, hasta cantar con ella la doctrina cristiana. Sin embargo, las lenguas y cultura sobrevivieron a esta castellanización“".

En el México Posrevolucionario, los esfuerzos para recuperar las lenguas y culturas que se estaban extinguiendo por el proceso de 
castellanización se iniciaron en 1940, al final del período del presidente Cárdenas, con el Primer Congreso Indigenista Interamericano en Pátzcuaro, Michoacán. La reflexión principal era poner en relieve las costumbres, creencias, hábitos, lenguas y expresiones artísticas; en sí, restaurar el respeto a la dignidad del indio (Greaves, 1999).

En este sentido, para 1949 se crea el Instituto Nacional Indigenista (INI), instancia creada para dar apoyo institucional federal a este sector vulnerable de la población mexicana. En los años subsecuentes, lo más destacable en los años sesenta es la aparición de los libros de texto gratuitos, esto con la idea de homogeneizar la educación nacional, que todos los niños contaran con libros de texto y que tuvieran la misma calidad educativa. En consecuencia, la educación indígena se vio fortalecida al tener un reconocimiento identitario que respondiera a una educación cultural diferenciada de la nacional pero paralela a esta última. Recordemos las Cartillas que se realizaron para cada etnia siguiendo la metodología de los libros de texto gratuitos; en los primeros años se enseñaba a leer y escribir en su idioma materno (la lengua ancestral) y no es sino hasta tercer año que inicia la enseñanza del español, bilingüismo que de acuerdo a las reformas se asume o se abandona (Stavenhagen, 1979).

A finales de la década de los ochenta, la Modernización Educativa planteaba la necesidad de mejorar la calidad educativa a nivel nacional. Durante más de treinta años el país se ha visto involucrado en una serie de reformas; por ejemplo, ubicándonos en este siglo (XXI) el presidente Fox plantea como objetivo en su primer informe de gobierno incorporar a la población vulnerable y marginal al proceso de desarrollo; para ello se comprometió a incrementar la cantidad y calidad de la educación. En el año 2011 surge otra Reforma Educativa que planteaba "la incorporación de estándares curriculares que permiten llevar un seguimiento longitudinal de los estudios de preescolar hasta secundaria.

En este año 2017, La Secretaría de Educación Pública plantea de nuevo una Reforma Educativa que tiene como objetivo la escuela al centro y la gestión de la administración como principales elementos a incorporar. En este contexto se plantean directrices para mejorar la atención educativa de niñas, niños y adolescentes indígenas, así como las dimensiones que debe abarcar el perfil del docente.

La educación en México ha estado embullida en procesos de cambios atropellados, donde el común denominador son las propuestas sexenales que, de acuerdo a las necesidades políticas del momento cada presidente de la república siente la necesidad de reformar, y cuyos procesos no culminan y son descartados por nuevos procesos que tampoco han alcanzado sus objetivos. Esto genera un círculo vicioso, dejando un rastro de buenas intenciones y pocos buenos resultados. De la misma manera, en el discurso se habla de una 
educación integral, de calidad, inclusiva, intercultural, entre otras; discurso aplicado a las necesidades del país pero que resulta utópico al momento de aplicarlo. La falta de planes de largo aliento ha conducido a un exceso en la discursividad y el abandono de lo esencial; es decir, de las metas y objetivos más relevantes que eviten el exterminio y deformación de las bases culturales y el desarrollo moral y económico de los grupos más vulnerables, lo que ha provocado igualmente la marginación y extrema pobreza vinculada a la condición étnica.

La práctica docente del profesorado de nivel básico en Presidio de los Reyes no ha sido evaluada; sólo el aprendizaje de los niños" es el que tiene un estándar de desempeño establecido, por lo que el docente pareciera estar invisible para las autoridades. Más aún, no se les ha preparado para una enseñanza basada en competencias.

Este proyecto fue considerado al analizar dos procesos claves en la educación: primero el de enseñanza-aprendizaje en sí mismo y el segundo las implicaciones en un segmento de población que no ha sido estudiada y es tomada como altamente vulnerable: los docentes indígenas. En este sentido, es necesario precisar si estos procesos que se tienen en la primaria y afectan el estándar de egreso del estudiante, con cambio en la metodología o en la planeación, van a coadyuvar a la apropiación de sus saberes culturales y formas de ver el mundo, aunado además al hecho de que se rescatarían conocimientos unicos de estas culturas. Recordemos que estos pueblos representan culturas vivas y lenguas ancestrales que cada vez se van perdiendo por la vorágine de la posmodernidad y el contacto con otras culturas; de ahí la importancia actual del esfuerzo por su comprensión, y que sigan siendo parte del patrimonio histórico cultural mexicano.

Anteriormente, se había comentado que una de las agendas pendientes que tiene el gobierno mexicano es la educación indígena, que si bien se han hecho esfuerzos, en poco o en nada han influido en detener el deterioro y la exterminación de las culturas y lenguas vivas. Es importante aclarar que la educación en México es homogénea; esto es, los programas y planes de estudio son los mismos para toda la república, tanto para escuelas privadas como públicas. Sin embargo, el país presenta diversos contextos geográficos, culturales, lingüísticos y, desde luego, económicos y políticos que requieren de un abordaje de mayor complejidad para poder asumir la diversidad cultural de México (OCDE, 2010).

De igual forma, en el devenir de este siglo han surgido una serie de propuestas educativas como las Escuelas del Milenio, de Tiempo Completo, de Calidad, Escuelas al 100, por mencionar solo algunas. También existen diferentes reconocimientos como escuelas Urbanas, Rurales y las que se ubican en contextos interculturales, siendo estas últimas el objeto de nuestra investigación (Díaz-Barriga, 2017). 
En principio, las escuelas interculturales son las que se ubican en la montaña, en la sierra, en el desierto, lejos de las poblaciones urbanas y son geográficamente de difícil acceso; se ubican en poblaciones altamente vulnerables que, por lo general, no cuentan con las mismas costumbres, cosmovisiones, tradiciones; incluso hablan una lengua diferente al español como es el caso de Presidio de los Reyes, localidad donde se habla Cora con la variante Meseño (la lengua Cora tiene cinco variantes: Mariteco, San Francisqueño, Corapeño y Tereseño) (Jáuregui, 2004).

En este contexto inter y multicultural se busca conocer cómo es que los docentes de la comunidad de Presidio los Reyes enfrentan esta situación; ¿es eficiente su trabajo con los estudiantes de primaria para que puedan llevar acabo los procesos de enseñanza- aprendizaje, como lo plantea la Secretaria de Educación Pública? (SEP, 2017); ¿sí han sido capacitados para el nuevo modelo?; ¿cuentan con el material o el apoyo necesario para hacer su labor educativa, y sí modifica o no el plan de estudios para desarrollar el proceso de enseñanza-aprendizaje?

La educación básica es un pilar esencial para todos los mexicanos ya que es la formadora de la ciudadanía y tiene como objetivo brindar competencias, los valores y capacidades que les permitan adaptarse a los cambios de la globalización e insertarse en el mercado laboral para muchos de ellos.

\section{El enfoque del aprendizaje en el nivel básico}

El enfoque basado en el constructivismo y las competencias, permite que el estudiante desarrolle habilidades y destrezas donde el docente juega varios roles: trasmisor, monitor, animador, supervisor, o guía del proceso de enseñanza-aprendizaje. ¿Qué sucede cuando el docente tiene que facilitar el aprendizaje? ¿Cuál es su rol? Velázquez (2012), Perrenoud (2014), y García et al. (2011).

En el modelo de competencias, aprendera aprender es una implicación relevante en el modelo curricular. En efecto, el aprendizaje contribuye al desarrollo del niño llevándolo a estar en la capacidad de "elaborar una representación sobre un objeto de la realidad o de un conocimiento que intentamos aprender, lo cual implica aproximarnos a dicho objeto o contenido con la finalidad de aprehenderlo en base a su experiencia previa"(Araoz, et al., 2010, p. 7). Esta experiencia modifica también el aprendizaje del nuevo conocimiento y se integra al internalizarlo lo que permite una construcción con un significado propio y personal.

\section{Secuencias didácticas}

Las secuencias didácticas se establecen a partir del currículo del nivel básico. Estas se pueden realizar para una asignatura, módulo o para cada una 
de las partes componentes. Sin embargo, no se debe realizar para una sola clase sino para dos o más sesiones, solicitándose un máximo cinco sesiones para la evaluación docente 2017-2018 (SEP 2017).

De acuerdo a Tobón (2010) y Velázquez, los programas educativos de nivel básico señalan los contenidos que un estudiante debe dominar, los cuales sirven para desarrollar las competencias y que los estudiantes dominen la información con el fin de que a partir de ella no sólo dominen conceptos sino que también desarrollen habilidades que pongan en juego las actitudes necesarias para que se organicen para resolver problemas o situaciones. de esta manera situar o ubicar un problema, las competencias aplicables, constituir las actividades de aprendizaje y evaluación, las cuales deben de estar articuladas y tener coherencia entre sí.

La secuencia didáctica cuenta con tres momentos: inicio, desarrollo y cierre. En la actividad de inicio, se lleva a cabo el encuadre, se presenta el programa, las normas del grupo, las actividades y los criterios de evaluación. En segundo lugar, se tiene el desarrollo de actividades de acuerdo a las instrucciones previas con el acompañamiento del docente, y en tercer momento la actividad de cierre, momento para el cual se tienen otras tres actividades: exposición por parte de los equipos, evaluación usando las rúbricas y la retroalimentación.

En la introducción de acuerdo a Velázquez, et al. (2012), Tobón (2010), Díaz-Barriga (2017) el docente debe formular preguntas detonadoras acerca de la temática, responder dudas, hacer lluvia de ideas para saber qué conocimientos previos tiene el estudiante acerca del tema y de ahí partir al siguiente momento.

Para la actividad de desarrollo, se inicia con las instrucciones de las actividades a realizar y describir las características del proceso y producto que se obtendrá de acuerdo al enfoque de competencias. Aquí se define la forma del trabajo y organización; posteriormente se debe informar sobre los recursos que se van a utilizar y lo que no está permitido. En el enfoque por competencias se trabaja para distribuir tareas entre los grupos y el docente se convierte en monitor, resuelve dudas, da sugerencias y hace aportes a los equipos.

Durante esta etapa se determina primeramente el propósito de las actividades a desarrollar; se debetomar en cuenta el verbo operativo (elaborar), la organización (equipos, pares, etc.), la estrategia, el criterio de exigencia (con material reciclable), el contenido o tema (ejemplo: una reproducción celular) y elcontexto (ejemplo, exponga el producto realizado al grupo).

\section{El perfil docente en educación básica primaria y sus dimensiones}

Las dimensiones del perfil docente son las funciones, habilidadesy destrezas que debe tener el docente. 
La Dimensión uno se refiere al conocimiento del niño en educación básica y puede describir las formas en que un niño aprende y cómo aprende a aprender, el plan de estudios. De la misma forma, esta dimensión se refiere a la capacidad de analizar los propósitos del enfoque educativo y los contenidos del currículo vigente que permite al docente dominar los aprendizajes esperados de cada grado y por lo tanto los resultados que debe de obtener por parte de cada estudiante.

En lo que respecta a la Dimensión dos, esta concierne a la organización, práctica docente y evaluación de los aprendizajes. De ahí que el docente deba tener habilidades de planeación, organización y evaluación. Lo anterior le permitirá aplicar estrategias de acuerdo a las necesidades de los estudiantes y crear ambientes de aprendizajes que favorezcan el aprendizaje.

En la imensión tres el docente se reconoce como un profesional que mejora continuamente, para apoyar así a los alumnos en su aprendizaje.

En la Dimensión Cuatro el docente asume las responsabilidades legales y éticas inherentes a su profesión para el bienestar de los alumnos.

En la Dimensión cinco el docente fomenta el vínculo de la escuela y la comunidad para asegurar que todos los alumnos concluyan con éxito su escolaridad (SEP,2017).

\section{Metodología}

El presente proyecto tiene un enfoque mixto cuanti-cualitativo y transversal. Para este trabajo sólo se presentan los resultados cualitativos, representados por las cuatro entrevistas realizadas a las profesoras de la Escuela Pentecatl de Presidio de los Reyes municipio de Ruiz, en el estado de Nayarit. Dichas entrevistas giran en torno a la dimensión uno y dos del perfil deseable del docente ideal en la Educación Básica de Segundo Nivel establecido por la SEP, dimensiones que implican el conocimiento del docente acerca del niño y su contexto escolar y familiar, al igual que la planeación y las preparación de las secuencias didácticas para determinar si existe una vinculación de los conocimientos académicos con los saberes tradicionales.

\section{Sujetos}

Los sujetos de esta investigación fueron los docentes de la Primaria Pentecatl, 8 profesoras y 3 profesores, y 1 directivo. El rango de edad esta entre los 32 y los 55 años de edad. Su antiguedad laboral fluctúa entre los 8 y 30 años. El 100\% de los docentes es egresado de la Universidad Pedagógica Nacional (UPN); sin embargo, es relevante que sólo 55\% del total de los docentes que enseñan en esa Primaria no se sienten satisfechos con su formación docente y mencionan que esta Institución les dio los elementos básicos, y algo de práctica pero no la suficiente por sólo asistir en períodos vacacionales. 
De los docentes, seis de ellos tienen un alto dominio de la lengua Cora en la variante MESEÑO. De ellos tres sólo comprenden la lengua Cora y sólo dos dominan la lengua Huichol (Directivo). 1 docente no habla ninguna lengua indígena.

\section{Resultados}

De la entrevista semi-estructurada de la primera dimensión y el analisis de las secuencias didácticas se tienen los siguientes resultados:

\section{Pregunta No. 1}

Con esta pregunta básica se establece el conocimiento que tiene el docente sobresus estudiantes y de qué manera utiliza el contexto en sus procesos de enseñanza-aprendizaje.

“... diagnostico, observo cómo el niño se relaciona con la comunidad, padres de familia, compañeros, tomo en cuenta ámbito geográfico, cultural, social”. Docente No. 1

“...sí identifico el contexto, pero mis estudiantes no hablan la lengua cora; de todos modos aplico lo de la lengua indígena, la asignatura y hacemos palabras en Cora o pequeñas oraciones y es lo que se puede hacer porque están muy chiquitos "... Docente No. 3

“...Adaptandome a las necesidades de ellos, pues tienen costumbres en cuanto a la realización de sus tradiciones, ellos tienen fiestas tanto religiosas como de las costumbres que ellos tienen de su etnia”... Docente No. 4

"...la mayoría de mis alumnos hablan español, son coras pero no hablan su lengua, no la practican porque en su casa sus papás ya no les hablan en cora. Les da vergüenza, incluso llevamos la asignatura de lengua indígena y cuando se trata de dialogar, ellos me responden en español, asi yo les hable en cora”... Docente 5

Tomando en cuenta las respuestas es posible afirmar que las profesoras sí identifican el contexto de sus estudiantes, lo consideran en los procesos enseñanza-aprendizaje en el aula y cumplen a cabalidad con el perfil establecido por la SEP (2017), aunque refieren tener ciertos problemas por el uso de la lengua ancestral. De acuerdo a Jáuregui (2004) la comunidad de Presidio de los Reyes es una comunidad nueva que se formó en loscincuenta, comunidad donde se tiene un fuerte contacto con mestizos. Esta puede ser una causa probable para el uso del español y la enseñanza de los docentes en lengua español que no apoya el uso de la lengua Cora, lengua que muchos niños sólo comprenden.

Con respecto a la lengua que hablan los docentes se puede establecer que la mitad de los grupos podrán aprender la lengua Cora como lengua extranjera porque varios docentes tienen un alto dominio de ella. Sin embargo, 
no poseen los materiales académicos en su lengua materna y sólo trabajan dos horas por semana, el cual es un tiempo insuficiente para adquirir una lengua como materna.La meta más ambiciosa que se podría alcanzar sería el aprendizajede la lengua Cora en su nivel más básico, vocabulario y algo de gramática. Las costumbres y la cultura general serán más fáciles de trasmitir que la lengua originaria, la cual requiere de una metodología diferente para ser adquirida como una segunda lengua.

\section{Pregunta 2}

Para la planeación de las actividades del aprendizaje es importante que el docente conozca las necesidades específicas de los estudiantes, lo cual es parte esencial del desarrollo de la primera dimensión.

“...implementé un test para identificar qué tipo de aprendices son: auditivos, quinestésicos o visuales. La mayoría salió visual, seis eran quinestésicos y los demás auditivos. Desarrollo además diversas actividades; cuando inicié tenía seis niños que no sabían leer ni escribir, hice actividades de primer grado, aquí se llaman de primer nivel, segundo nivel les falta más fluidez en la lectura, los de tercer nivel que es mi nivel son los que ya dominan la lectura, la escritura, las palabras compuestas $u$ oraciones "... Docente 1

“... Una buena alimentación, los padres carecen de fuente de empleo y no es lo mismo para que los niños tengan un aprendizaje significativo"... Docente 2

"...una necesidad que tienen los niños es que no tienen para comer, la mayoría vienen sin almorzar, bueno, como unos cinco”... Docente 3

“... todos requieren la atención más que nada de los padres, porque la mayoría de los niños viven con los abuelos y no los atienden como debe ser. Faltan a la escuela, no cumplen con sus tareas, trabajos, y a las reuniones no vienen" ... Docente 4

"...que ellos tengan interés, vienen, pero no traen el interés de aprender, sus papás los mandan y no se hacen responsables “... Docente 5

Como se puede observar, las profesoras presentan problemáticas diversas y complejas. Por un lado, hay carencia alimentaria y de atención general adecuada por parte de los padres de familia. De acuerdo a García (2011) los factores negativos que influyen en el proceso enseñanza-aprendizaje y al mismo tiempo lo obstruyen, dando pauta al bajo rendimiento, son elementos a considerar por parte de las profesoras. Por otra parte, reconocen los tipos de aprendizaje que manejan sus estudiantes y desde luego lo consideran en la planeación didáctica que promueve un aprendizaje de calidad. De igual forma sus actividades de clase son variadas, esto de acuerdo a las necesidades de sus estudiantes. La escuela tiene un programa de apoyo al 
desayuno escolar donde los niños aportan 1 peso diario simbólico para este fin,que se les de desayuno; incluso al que no puede darlo no se le niega el alimento.

\section{Pregunta 3}

Por tratarse de una "comunidad étnica" es importante recuperar los saberes ancestrales, de ahí entonces que sea necesario conocer cómo los profesores promueven o no estos saberesy si lo relacionan con los contenidos académicos y la vida moderna nacional.

“... sí, los niños realizan narraciones de las costumbres, mitos, leyendas y las narraciones en ambas lenguas (español y cora); por ejemplo, la leyenda del nombre del pueblo "Presidio de los Reyes"; las fiestas tradicionales, "Las Pachitas" para la Semana Santa Cora, los estudiantes elaboran sus instrumentos, sus máscaras y se pintan el cuerpo, esta actividad se toma en cuenta en la asignatura artística”... Docente No. 1

“...sólo elaboro material; el año pasado tuvimos el proyecto Escuelas de Calidad y ahi realicé uno. He trabajado con los estudiantes adivinanzas, tarjetas de palabras de la lengua materna, cuentos y cantos en la lengua materna” ... Docente No. 2

"...las fiestas tradicionales, las pachitas, las danzas; en enero se empiezan con la entrega de cargos y cada una de ellas los incluyo en los bloques" ... Docente No. 3

"...Sí, hemos participado en eventos dentro de la zona escolar, concurso de escoltas, del himno nacional en lengua ancestral, etcétera" ... Docente No. 4

En general las docentes dicen utilizar y desarrollar materiales didácticos que están relacionados con las narrativas de la asignatura Español y Artística y con ello promueven la conservación de la cultura y la lengua naayeri (cora). Tobòn (2010) y Velázquez (2012) establecen que en el enfoque basado en competencias el docente debevincular el saber académico con la realidad y contexto de los estudiantes. Por ejemplo, una de las estrategias que se puede utilizar es la simulaciòn de un contexto, que es lo que pone en práctica el docente de artística al realizar máscaras y dejar que los niños se pinten el cuerpo de acuerdo a la costumbre de la semana santa cora, además de promover los concursos de escoltas donde los niños usan su traje tradicional y cantan el himno nacional en la lengua cora, lo cual representa un apoyo a la identidad Cora en los niños (Jauregui, 2004).

\section{Pregunta No. 4}

A partir de esta pregunta se indaga si las docentes promueven actividades que fomentan la cultura naayeri. 
“... les encargo que investiguen con sus padres el nombre de ciertos animales o cosas y lo aplico también en matemáticas, por ejemplo, les pido que indaguen cómo se pronuncian y escriben números en nayeri (cora) "... Docente No. 2

".. no, sólo en la evaluación diagnóstica que elaboro al inicio del ciclo escolar, no" ... Docente No. 4

"...Casi no lo hemos trabajado, lo trabajamos dos horas por semana, dos horas y media a la semana; nos estamos enfocando más a las otras asignaturas" ... Docente No. 5

Como se puede observar sólo tres maestras contestaron a esta pregunta: dos de ellas (solo el 50\%) aducen realizar actividades que fomentan la cultura y el $25 \%$ dice que no lo hace. Esto también denota una falta de interés o quizás de conocimiento sobre la lengua, además de aceptar que no se le dedica tiempo suficiente al desarrollo de la cultura ancestral. De acuerdo al cuestionario de datos demográficos $10 \%$ de los docentes hablan la lengua huichol y el otro $10 \%$ no hablan lengua indígena; siendo esta posiblemente una causa que dificulte el vincular actividades hacia la comunidad y la lengua. De acuerdo a Estevez (2003) esta orientación hacia los saberes tradicionales y al contexto de los estudiantes permitirá que los estudiantes establezcan relaciones de información y la puedan organizar para adquirirla.

En las respuestas vertidas de las docentes sobre esta primera dimensión que implica conocer a sus estudiantes, cómo aprenden y qué deben aprender acorde al contexto intercultural de los mismos (Perrenoud, 2014) se puede concluir que ellas están inmersas en los procesos culturales de sus estudiantes y retoman estas prácticas en los procesosdel aula; sin embargo, el tiempo que le dedican no es suficiente y sólo están aprendiendo la lengua como en otros contextos se aprende una lengua extranjera. También se pudo analizar analizar que algunas maestras no hablan la lengua naayeri.

Por otra parte, de acuerdo a García et al. (2011) los materiales juegan un papel importante en el aprendizaje, y en este caso si la SEP (2017) quisiera que los niños de contextos interculturales aprendieran Cora en la variante Meseño, ellos producirían los textos académicos en su lengua. Sin embargo, el cora es una lengua minoritaria y no se crean estos materiales (INEE, 2014).

\section{DIMENSIÓN SEGUNDA \\ Pregunta 2.1}

Ante estos contextos multiculturales es importante conocer cómo las profesoras diseñan sus actividades de aprendizaje, y al respecto comentan:

“...hacer dinámicas que fomenten el respeto y los llevo a concursos a otras comunidades y se pone de ejemplo. Cuando un estudiante no habla español, utilizo niños traductores que hablan cora y español y 
ellos me auxilian. Uso imágenes y las relacionan con la palabra”.... Docente No. 1

“...Uso memoramas, loterías para trabajar los saberes tradicionales”... Docente No. 2

“...por ejemplo en la festividad de las pachitas, saco a los niños del salón en el recreo cuando pasan por aquí y las dejo meter (Pachitas) y los niños bailan con ellas, posteriormente les hago preguntas o les pido que dibujen sobre el significado de esa fiesta”... Docente No. 3

"... al trabajar el proyecto de guión radiofónico hicieron audios para que sus compañeros escucharan sobras las fiestas que se celebran en su comunidad, tuvieron que hacer investigación del significado de las fiestas aunque no tuvieron mucha información porque sus padres desconocen también" ... Docente No. 5

Las respuestas nos confirman el fomento de la cultura naayeri y la integración de los contenidos académicos con el desarrollo de estos procesos culturales. Retomamos lo que Tobòn (2010), García, et.al. (2012) y Estevez (2003) proclaman que para tener un conocimiento significativo se deben vincular los conceptos y la teoría con la realidad del estudiante para que él pueda construir su conocimiento nuevo e integre los previos al mismo tiempo. De la misma manera, al tener el estudiante esta vinculacion con la cultura se le forma integralmente con valores y se fortalece la identidad Nayeri.

\section{Pregunta 2.2}

La pregunta indaga sobre la planeación de los conocimientos académicos y conocer cómo se vinculan con los saberes y celebraciones tradicionales, esto con el objetivo de saber si hay una aprehensión de los mismos y notar la forma de evaluación que se lleva a cabo con las asignaturas de la primaria.

“...si, a través de la evaluación sumativa que es la calificación del bimestre, la formativa la uso para todo, evaluó los valores. La evaluó a través de una lista de cotejo con los valores que ya establecí y lo anexo a su calificación sumativa. Trabajo estos saberes cada 15 días con la asignatura de lengua indígena o mínimo una vez a la semana”... Docente No. 1

“...lo hacemos una vez a la semana nos toca lengua indígena, bueno dos, jueves y viernes, y se tienen que incluir las actividades en nuestras planeaciones. Los evaluó de manera escrita y oral, y los incluyo en la evaluación formativa "... Docente No. 2

“...constantemente hago evaluaciones”... Docente No. 3

“...si, elaboro un examen escrito en donde van preguntas, imágenes, donde ellos relacionan la pregunta con su respuesta de acuerdo con lo que se trabajó en la lengua 2... Docente No. 4 
“... a veces, los evalúo con la participación”... Docente No. 5

Las profesoras utilizan la evaluación formativa, sumativa a través de exámenes (no mencionan rúbricas, ni listas de cotejo) y en el mejor de los casos, evalúan la participación(evaluación formativa), olvidando el contexto y su "uso" en la cotidianidad; es decir, en la vida social de la comunidad que es en donde en realidad se demuestra que han aprendido y pueden recrear la lengua, la cultura y reforzar su identidad. Velásquez (2012), Estevez (2003), y Velazquez (2012), nos dicen que en el constructivismo el estudiante emplea los conocimientos previos y losconjunta con los nuevos para construir su propio conocimiento. Sin embargo, el docente olvida algo muy importante: la evaluación del producto y la retroalimentación donde el estudiante habla de la limitaciones que se tuvieron y se le dan a conocer los aspectos a mejorar.

\section{Secuencias didácticas}

Para este estudio sólo tomaremos las asignaturas de Español de sexto año, Lengua Indígena en el análisis de vinculación de saberes acadámicos y la asignatura Conocimientos Ancestrales.

La planeación didáctica de un docente de educación básica debe estar inspirada en el modelo por competencias con el estudiante al centro, es decir, como producto basado en los aprendizajes esperados y en la temática establecida en los libros. La evaluación de los aprendizajes debe ser sobre el saber, el saber hacer y ser Perrenoud (2014), Tobón (2010), García (2011), Díaz- Barriga (2009), consistiendo de esta manera la planeación en varios momentos el primero donde se analiza, piensa y diseñan los ambientes de aprendizaje centrado en el estudiante con las actividades de apertura, desarrollo y cierre. Todo esto se realiza a través de una secuencia didáctica.

SEXTO AÑO

\section{Bloque II. Competencias:}

i. Emplear el lenguaje para comunicarse como instrumento para aprender.

ii. Identificar las propiedades del lenguaje en diversas situaciones comunicativas. Analizar la información y emplear el lenguaje para la toma de decisiones.

iii. Valorar la diversidad lingüística y cultural de México.

Aprendizajes esperados: Identifica características generales de los reportajes y su función para integrar información sobre un tema.

a. Comprende e interpreta reportajes.

b. Selecciona información relevante de diversas fuentes para elaborar un reportaje.

c. Emplea notas que sirvan de guía para la escritura de textos propios, refiriendo los datos de las fuentes consultadas.

Materiales: libro, cañón, computadora, pantalla. 
Producto final/ Práctica social del lenguaje:Escribir un reportaje sobre su localidad. / De acuerdo al libro el producto final debe ser la publicación del reportaje en su municipio o localidad.

Tipo de texto: expositivo.

De acuerdo a la observación no participante, la docente después de hacer las preguntas detonantes les informa a los estudiantes el producto final del tema y, luego procede a darles las instrucciones del material y cómo lo va a evaluar.

Con respecto al ambiente del aula, este es bastante caluroso y no hay abanicos suficientes para los niños; la docente cuenta con el material adecuado para dar su cátedra y además hace de las TICs (uso de cañón y computadora) para mostrar a los estudiantes las especificaciones del producto que entregarán.

La docente habla acerca de las costumbres en la comunidad, los niños usan su vestido tradicional y en la cátedra siempre se relaciona el conocimiento académico y el desarrollo de habilidades comunicativas y de redacción del español, al mismo tiempo que se lleva a cabo una toma de notas sobre las tradiciones de la Comunidad Cora.

Por otra parte, con respecto al análisis de la secuencia didáctica, de acuerdo a Perrenoud (2014) la educación básica define lo que el niño debe saber, saber hacer y ser sin importar si fue la educación formal, no formal o informal. Sin embargo, el currículo no establece la importancia de la cultura, y la cultura indígena sólo se menciona en los conocimientos académicos que se refieren a la lengua indígena. A pesar de esta gran omisión por parte de las autoridades, la docente vincula el saber académico con el tradicional y permite que los niños también realicen esta conexión entre sus conocimientos previos y el académico. De igual manera relacionan la producción de un tema como realizar un reportaje y lo vinculan con la comunidad Cora al escribir el reportaje acerca de su contexto (Esteves, 2003; García et al., 2011), contexto donde el niño tiene metas de aprendizaje y trabaja en forma colaborativa.

\section{ESPAÑOL}

Bloque I. Tema: Conociendo mis costumbres.

Competencia: Emplear el lenguaje para comunicarse como instrumento para aprender.

Aprendizaje esperado: Anticipa el contenido de un texto a partir de la información que se le proporciona.

Establece correspondencia entre escritura y oralidad al leer sobre problemas. Material: Papel picado, hilaza, papel lustre, alimentos del Día de Muertos

\section{Secuencia didáctica}

En la secuencia didáctica de la docente se habla acerca de la leyenda de terror de La Llorona,introduce las festividades de la comunidad y estructura su 
planeación con preguntas detonantes acerca de la festividadades: Año nuevo, Semana Santa y termina con la celebración del Día de los Muertos.

El producto final de la secuencia será diseñar un altar para participar en el concurso de altares, como es costumbre en la comunidad, y hacer una descripción del significado de cada cosa que se usa en dichos altares. La docente introduce los objetos del altar en lengua Cora y los niños dibujarán dichos objetos para relacionar el nombre con su imagen.

De la misma manera, las docentes piden a los estudiantes escribir"calaveritas" (son rimas acerca de una persona y la relacionan con la muerte, son muy populares en México en el Día de los Muertos).

En relación a esta secuencia Velázquez (2012) y Tobón (2010) establecen que se deben tener competencias genéricas y transversales para la vida; éstas comprenden el saber, y saber hacer. La docente, en forma adecuada, vincula el saber redactar una descripción con una festividad, y los estudiantes, terminan por redactar una rima del tema establecido en la secuencia;esto permitirá que el niño construya su conocimiento nuevo a partir de los previos y tenga la experiencia de comunicar con sus compañeros su rima y descripción acerca de la festividad mencionada.

\section{Conclusion}

En este estudio analizamos las primeras dos dimensiones de la labor docente, las cuales tienen que ver con el contexto del niño y el conocimiento de éste por parte del profesor. De igual manera se analizó su intervención didáctica, organización y evaluación, así como la planeación implícita en las secuencias didacticas de los docentes para conocer si existe alguna vinculación de los saberes academicos con los ancestrales. En este sentido, las docentes realizan un esfuerzo loable al tratar de promover, acorde a los requerimientos de los programas de la SEP, los saberes ancestrales,fomentar la cultura naayeri y tratar de vincular los conocimientos academicos de las asingaturas de español, matemáticas y lengua indígenas. Sin embargo, la carga académica de los contenidos curriculares hace difícil esta actuación y vinculación específicamente con la comunidad Cora.

Si bien el director de la escuela ha promovido un acercamiento de las autoridades tradicionales como lo son el "gobernador" y "el cantador de la música tradicional" con la escuela, y aunque las maestras dicen celebrar las fiestas tradicionales en la escuela como el Día de muertos, evento dondese realiza un concurso de altares en base a las costumbres Nayeris y a los cuales dichas autoridades asisten con frecuencia para interactuar con los niños, son necesarias más acciones donde los infantesrefuercen y estimulen la identidad naayeri, la cultura y la adquisición de la lengua, aún si se usan las metodologias para enseñarla como si fuera una segunda lengua. 
En este sentido, aprendimos que los estudiantes habitan la escuela como una entidad diferenciada de la comunidad. En ella aprenden saberes académicos con una relación poco estrecha con su cultura ancestral; los pocos elementos que se viven y recrean en el aula, como los reportajes de la comunidad vinculados con la asignatura de español entre otros, están descontextualizados de su cotidianidad y de su entorno.

Aunado lo anterior, y a la presión que ejerce el contacto con otras culturas, los problemas económicos que provocan la descomposición de las familias tradicionales, el mundo globalizado, las nuevas formas de comunicación y el uso mayoritario que hacen de la lengua dominante (español), provocan en los estudiantes, nuevas significaciones en la cosmovisión naayeri que van transformando su presente $\mathrm{y}$ futuro. La castellanización hace que vean los niños su realidad de una manera más occidentalizada, dejando fuera poco a poco la identidad naayeri y conllevando en consecuencia a la pérdida de saberes ancestrales que han sobrevivido desde la conquista cada vez más deformados y deteriorados en camino a la extinción ante la indiferencia o la importancia institucional educativa y social.

\section{References:}

1. Araoz, M., Guerrero, P., Galindo, M., Villaseñor, R., \& De la Vara, A. (2010). Estrategias para aprender a aprender. Segunda Ediciòn. Pearson. Mèxico.

2. Díaz, A. (2017). La Docencia y evaluación en la Reforma Educativa 2013 Recuperado el 3 de enero 2017 de:http://www.iisue.unam.mx/libros/

3. Estévez, E. (2003). Enseñar a aprender: estrategias cognitivas. Paidos. México.

4. García, C., Arranz, Ma., \& Luisa (2011). Didáctica de la educación infantil. Editorial Paraninfo. España

5. Gonzalbo, P. \& Ossenbach, G. (1999). "La educación rural e indígena en Iberoamérica”. México, D.F. El colegio de México. Centro de Estudios Históricos. 2da Reimpresión

6. Greaves, C. (1999). "Proyectos y realidades de las misiones culturales": UNAM-JIH Edición, la ciudad y el campo en la historia de México, Vol. II México

7. Jáuregui, J. (2004). Coras Pueblos indígenas del México contemporáneo. México: CDI : PNUD, México. ISBN 970-753-032-4.

8. OCDE (2010). Acuerdo de cooperaciónMéxico-OCDE paramejorar la calidadde la educación de lasescuelas mexicanas.

9. Perrenoud Philippe (2014). Cuando la escuela pretende preparar para la vida, ¿Desarrollar competencias o enseñar otros saberes? Editorial Grao. México. 
10. Stavenhagen, R. (1979). México: minorías étnicas y política cultural. Rev. Nexos. Julio. México, D.F. día 03/01/2017 de: https://www.oecd.org/edu/school/46216786.pdf

11. Velásquez, J. \& Frola, P. (2012). Escuelas incluyentes. Editorial Frovel Educación. México.

12. Tobón, S. (2010). Formación basada en competencias. Pensamiento complejo, currículo didáctica y evaluación. Bogotá, Ecoe. 